Article

\title{
Enhanced Phosphate Removal from Water by Honeycomb-Like Microporous Lanthanum- Chitosan Magnetic Spheres
}

\author{
Rong Cheng $\left.{ }^{1} \mathbb{(}\right)$, Liang-Jie Shen ${ }^{1}{ }^{(D)}$, Ying-Ying Zhang ${ }^{1}$, Dan-Yang Dai ${ }^{1}$, Xiang Zheng ${ }^{1}$, \\ Long-Wen Liao ${ }^{2}$, Lei Wang ${ }^{3, *(1)}$ and Lei Shi ${ }^{1, *}$ \\ 1 School of Environment and Natural Resources, Renmin University of China, Beijing 100872, China; \\ chengrong@ruc.edu.cn (R.C.); shenliangjie@ruc.edu.cn (L.-J.S.); zhangyingying@ruc.edu.cn (Y.-Y.Z.); \\ daidanyang@ruc.edu.cn (D.-Y.D.); zhengxiang@ruc.edu.cn (X.Z.) \\ 2 Northwest Institute of Nuclear Technology, Xi'an 710024, China; liaolw16@tsinghua.org.cn \\ 3 Research Center for Eco-Environmental Sciences, Chinese Academy of Sciences, Beijing 100872, China \\ * Correspondence: leiwang@rcees.ac.cn (L.W.); shil@ruc.edu.cn (L.S.); \\ Tel.: +86-131-6103-1804 (L.W.); +86-138-1138-4632 (L.S.)
}

Received: 13 October 2018; Accepted: 12 November 2018; Published: 14 November 2018

\begin{abstract}
The removal of phosphate in water is crucial and effective for control of eutrophication, and adsorption is one of the most effective treatment processes. In this study, microporous lanthanum-chitosan magnetic spheres were successfully synthetized and used for the removal of phosphate in water. The characterization results show that the dispersion of lanthanum oxide is improved because of the porous properties of the magnetic spheres. Moreover, the contact area and active sites between lanthanum oxide and phosphate were increased due to the presence of many honeycomb channels inside the magnetic spheres. In addition, the maximum adsorption capacity of the Langmuir model was $27.78 \mathrm{mg} \mathrm{P} \cdot \mathrm{g}^{-1}$; and the adsorption kinetics were in good agreement with the pseudo-second-order kinetic equation and intra-particle diffusion model. From the results of thermodynamic analysis, the phosphate adsorption process of lanthanum-chitosan magnetic spheres was spontaneous and exothermic in nature. In conditional tests, the optimal ratio of lanthanum/chitosan was $1.0 \mathrm{mmol} / \mathrm{g}$. The adsorption capacity of as-prepared materials increased with the augmentation of the dosage of the adsorbent and the decline of $\mathrm{pH}$ value. The co-existing anions, $\mathrm{Cl}^{-}$and $\mathrm{NO}_{3}{ }^{-}$had little effect on adsorption capacity to phosphate, while $\mathrm{CO}_{3}{ }^{2-}$ exhibited an obviously negative influence on the adsorption capacity of this adsorbent. In general, owing to their unique hierarchical porous structures, high-adsorption capacity and low cost, lanthanum-chitosan magnetic spheres are potentially applicable in eutrophic water treatment.
\end{abstract}

Keywords: porous structure; lanthanum; La-chitosan magnetic spheres; adsorption capacity; phosphate; adsorption isotherm

\section{Introduction}

The eutrophication of water bodies has become one of the major ecological environmental issues all over the world [1-3]. Especially, phosphorus, an essential element for the growth of aquatic organisms, is one of the limiting elements for the eutrophication of water bodies [4]. Phosphate is involved in the aqueous environment by means of both natural activities and the affairs of people, such as significant erosion, mining, agricultural fertilization, and industrial operation. The presence of excess phosphorus in water further results into the outbreak of algal blooms, death of aquatic organisms, and sharp deterioration of water quality. In severe cases, cyanobacterial blooms, caused by an excess phosphorus in water, generally poses many difficult challenges to the stability of aquatic 
ecosystems and the protection of domestic water quality of residents. Therefore, the removal of excess phosphate in water is of great significance for controlling and preventing the deterioration of water bodies.

At present, the methods for phosphorus removal mainly include chemical precipitation [5], biological phosphorus removal [6], membrane separation [7], adsorption [8-10], and ion exchange [11]. For example, chemical removal including precipitation with aluminum, iron, and calcium components is a common means for effective removal of phosphorus from water. However, higher sludge production is led by this method, and harmless sludge treatment needs to be further considered [12]. Biological phosphorus removal has attracted much attention due to its advantages of no chemical additions. However, it is worth pointing out that the phosphorus removal effect of biotechnology is greatly affected by the operating conditions [13]. In many of the above methods, adsorption is a very promising method for efficiently removing phosphate from water. It presents several advantages of simple operation, less sludge generation, and the ability to recover phosphorus element without secondary pollution. However, due to the limited adsorption capacity of natural adsorbents, it is necessary to select new and efficient adsorbents.

Recent studies have found that metal oxides have a good adsorption effect on phosphate in the water bodies, especially oxides of transition metal elements (zirconium, hafnium, and lanthanum) which effectively increases the adsorption capacity of phosphate, such as hydrous lanthanum oxide, zirconium oxide [14,15]. Especially, lanthanum has attracted the interest of many researchers due to its non-toxicity, chemically stable, and extremely strong affinity for phosphate. To date, several studies about the phosphate adsorption performances of La-based adsorbents have been reported in succession all over the world. For example, the phosphate removal efficiency of $\mathrm{LaCl}_{3}$-modified kaolinite or pumice clays were almost $6-37 \%$ higher than those of pure clays [16]. The maximum adsorption of $25 \mathrm{mg} \mathrm{P} \cdot \mathrm{g}^{-1}$ and the phosphorus removal rate of $99 \%$ were reached by lanthanum-modified zeolite when the initial concentration of phosphate and $\mathrm{pH}$ is $30 \mathrm{mg} \cdot \mathrm{L}^{-1}$ and 4.0 , respectively. The maximum monolayer adsorption capacity of lanthanum-iron complex materials is $208.33 \mathrm{mg} \mathrm{P} \cdot \mathrm{g}^{-1}$ and it also has a high adsorption capacity for high concentration of phosphorous water. Although the above materials have good adsorption and stability, there are also several shortcomings, which also includes the difference between this lanthanum-chitosan magnetic spheres and above materials. For example, most of the adsorbents mentioned above are in powders state, which are difficult to be recovered and reused in water. The phosphate, adsorbed by the disposable adsorbents, will still be resolved into the water with time going on, resulting in eutrophication again. The problem has not been solved fundamentally.

Based on the above analysis, lanthanum-chitosan magnetic spheres were synthesized by an in situ chemical precipitation method. The combination of the advantages of lanthanum oxide and shaping characteristic of cheap and readily available magnetic chitosan was achieved to apply phosphate removal in water for the purpose of magnetic recovery of adsorbents and separation of phosphate from water. In addition, the honeycomb-like structures of as-prepared lanthanum-chitosan magnetic spheres in this study were formed to effectively improve the dispersity and utilization of lanthanum oxides. Moreover, very large specific surface area and active sites for phosphate adsorption are provided. Moreover, it is worthy of attention that the low temperature cryodesiccation technique, one of the means of maintaining the chemical composition and porous structure of materials, is applied to the preparation of the uniform honeycomb-like microporous spheres, different from the solid sphere in order to significantly increase the specific surface area of the composite spheres. And as-prepared spheres were characterized with different techniques (X-ray diffraction (XRD), Scanning electron microscopy (SEM), Fourier transform infrared spectroscopy (FTIR), and Vibrating sample magnetometer (VSM)) and the adsorption kinetics, isotherm, and thermodynamic analysis of phosphate by as-prepared adsorbents were further studied. Meanwhile, the influences of different experimental parameters (lanthanum/chitosan ratio, dosage of adsorbents, $\mathrm{pH}$ of solution, and coexisting anions) were also investigated to provide the reference for the practical application. 


\section{Materials and Methods}

\subsection{Chemicals}

Chitosan (analytical reagent, AR) was produced by Shanghai Aladdin Biochemical Technology Co., Ltd., Shanghai, China. Lanthanum (III) nitrate hexahydrate (guaranteed reagent, GR), was produced by Xilong Scientific Co., Ltd., Shanghai, China. Ferrous sulfate (GR), iron (III) chloride hexahydrate (GR), potassium phosphate monobasic (AR), hydrochloric acid (AR), acetic acid (AR), and sodium hydroxide (GR) were produced by Sinopharm Chemical Reagent Beijing Co., Ltd., Beijing, China.

\subsection{Preparation of Lanthanum-Chitosan Magnetic Spheres}

In general, chitosan magnetic spheres were prepared by the chemical precipitation method using alkali liquor as the firming agent. Firstly, approximately $2.0 \mathrm{~g}$ of chitosan was dissolved in $30 \mathrm{~mL}$ deionized water and $1.50 \mathrm{~mL}$ glacial acetic acid was subsequently added to create sticky liquid (solution A). Then $2.70 \mathrm{~g} \mathrm{FeCl}_{3} \cdot 6 \mathrm{H}_{2} \mathrm{O}$ and $1.65 \mathrm{~g} \mathrm{FeSO} \cdot 7 \mathrm{H}_{2} \mathrm{O}$ were dissolved in $10 \mathrm{~mL}$ ultrapure water and mixed (solution $\mathrm{B})$. A several amount of $\mathrm{La}\left(\mathrm{NO}_{3}\right)_{3} \cdot 6 \mathrm{H}_{2} \mathrm{O}(0,1.0 \mathrm{mmol}, 2.0 \mathrm{mmol}, 3.0 \mathrm{mmol}$, $6.0 \mathrm{mmol}$, and $10.0 \mathrm{mmol}$, respectively) was dissolved into $10 \mathrm{~mL}$ deionized water (solution C). Then solution B and solution C were added to solution A and then stirred for 30 min. Thirdly, with a constant current syringe pump, the mixed solution was dropped into a beaker containing $300 \mathrm{~mL}$ of $15 \mathrm{wt}^{\%} \mathrm{NaOH}$ at a rate of $2.0 \mathrm{~mL} \mathrm{~min}^{-1}$ using a $20 \mathrm{~mL}$ syringe. The prepared spheres were shaken for $1.0 \mathrm{~h}$, and then were frozen for $12 \mathrm{~h}$ by freeze drier. Finally, the material was placed in a constant-temperature drying oven for $2.0 \mathrm{~h}$ at $80^{\circ} \mathrm{C}$ and lanthanum-chitosan (La-chitosan) magnetic spheres were prepared. In addition, chitosan magnetic spheres were prepared by the same process without adding $\mathrm{La}\left(\mathrm{NO}_{3}\right)_{3} \cdot 6 \mathrm{H}_{2} \mathrm{O}$.

\subsection{Characterization of La-Chitosan Magnetic Spheres}

The surface morphology of as-prepared samples was concretely analyzed by scanning electron microscopy (SEM) (Nova 400 Nano, FEI Company, Hillsboro, OR, USA). The phase composition of the samples was monitored by X-ray diffraction (XRD) (D/MAX-AX, Rigaku Corporation, Tokyo, Japan). The functional groups of the samples were parsed in detail by Fourier transform infrared spectroscopy (FTIR) (IRTracer-100, Hitachi, Ltd., Tokyo, Japan). The magnetization intensity of the samples was analyzed by vibrating sample magnetometer (VSM) (Quantum Design MPMS XL7, Quantum Design, Inc., San Diego, CA, USA).

\subsection{Phosphate Adsorption Experiments}

\subsubsection{Adsorption Kinetics}

Phosphate adsorption experiments of this study were conducted by evenly mingling $0.5 \mathrm{~g} \cdot \mathrm{L}^{-1}$ of the La-chitosan magnetic spheres with $100 \mathrm{~mL}$ of a $\mathrm{K}_{2} \mathrm{HPO}_{4}$ solution at $100 \mathrm{rpm}$ and $25^{\circ} \mathrm{C}$. In addition, similar conditions have been also taken in kinetic experiments. The residual phosphate concentration of solution was determined accurately by a UV-VIS spectrophotometer (DR6000, HACH, Loveland, CO, USA) by the aid of the ammonium molybdate spectrophotometric method after filtration [17].

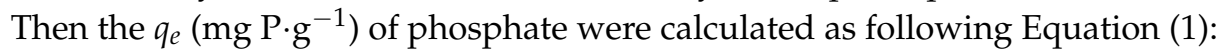

$$
\text { Adsorption capacity : } q_{e}=\frac{\left(C_{0}-C_{e}\right) V}{m}
$$

where $C_{0}$ represents the initial concentration of phosphate solution $\left(\mathrm{mg} \cdot \mathrm{L}^{-1}\right), C_{e}$ is the actual phosphate concentration of solution $\left(\mathrm{mg} \cdot \mathrm{L}^{-1}\right)$ at adsorption equilibrium, $V$ indicates the total volume of reaction liquid (L), and $m$ equals the dosage of as-prepared materials $(\mathrm{g})$.

For the research on adsorption kinetics of as-prepared materials, the experiments were carried out with $20 \mathrm{mg} \cdot \mathrm{L}^{-1}$ initial concentration of phosphate and $0.5 \mathrm{~g} \cdot \mathrm{L}^{-1}$ of La-chitosan magnetic spheres. 
The adsorption data were further fitted through a pseudo-first order kinetic model, pseudo-second order kinetic model and intra-particle diffusion model to probe into the kinetic mechanism, according to Equations (2)-(4), respectively [18]:

$$
\begin{gathered}
\text { The pseudo-first order kinetic model : } \log \left(q_{e}-q_{t}\right)=\log q_{e}-\frac{k_{1} t}{2.303} \\
\text { The pseudo-second order kinetic model }: \frac{t}{q_{t}}=\frac{1}{k_{2} q_{e}^{2}}+\frac{t}{q_{e}} \\
\text { Intraparticle diffusion model }: q_{t}=k_{p} t^{1 / 2}+C
\end{gathered}
$$

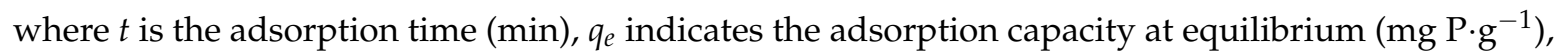

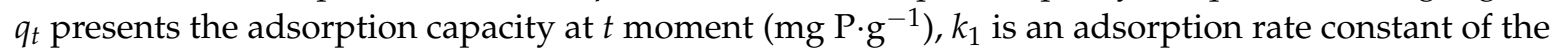
pseudo-first order kinetic $\left(\mathrm{min}^{-1}\right), k_{2}$ is an adsorption rate constant related to the pseudo-second order kinetic $\left(\mathrm{g} \cdot \mathrm{mg} \cdot \mathrm{min}^{-1}\right), k_{p}$ is a rate constant related to the intra-particle diffusion $\left(\mathrm{mg} \cdot \mathrm{g}^{-1} \cdot \mathrm{min}^{-1 / 2}\right)$, and $C$ presents a constant related to the boundary layer thickness.

\subsubsection{Adsorption Isotherm}

For the study on adsorption isotherms, experiments were carried out with $100 \mathrm{~mL}$ of phosphate solutions of different initial concentrations $\left(5,10,15,20,30,40 \mathrm{mg} \cdot \mathrm{L}^{-1}\right)$. The dosage of adsorbent was $0.05 \mathrm{~g}$, and the $\mathrm{pH}$ was adjusted to 7.0. After adsorption, the adsorption data of La-chitosan magnetic spheres were fitted by Langmuir Equation (5) and Freundlich Equation (6) $[19,20]$ :

$$
\begin{gathered}
\text { Langmuir equation : } q_{e}=q_{m} K_{L} \frac{C_{e}}{1+C_{e} K_{L}} \\
\text { Freundlich equation : } q_{e}=K_{F} C_{e}^{1 / n}
\end{gathered}
$$

where $q_{e}$ is the adsorption capacity at equilibrium $\left(\mathrm{mg} \cdot \mathrm{g}^{-1}\right), q_{m}$ is equal to the adsorption capacity at saturation $\left(\mathrm{mg} \cdot \mathrm{g}^{-1}\right), C_{e}$ indicates the concentration of phosphate in equilibrium state $\left(\mathrm{mg} \cdot \mathrm{L}^{-1}\right), K_{L}$ is a constant related to thermodynamics $\left(\mathrm{L} \cdot \mathrm{mg}^{-1}\right), K_{F}$ is a constant related to adsorption strength, $n$ is a constant related to adsorptivity.

In addition, the characteristics of the Langmuir isotherm model can be visually represented by the equilibrium parameter $\left(R_{L}\right)$, as shown in Equation (7):

$$
R_{L}=\frac{1}{1+K_{L} C_{0}}
$$

where $C_{0}$ is the initial concentration of phosphate in solution $\left(\mathrm{mg} \mathrm{P} \cdot \mathrm{L}^{-1}\right) ; K_{L}$ presents the Langmuir's adsorption constant $\left(\mathrm{L} \cdot \mathrm{mg}^{-1}\right)$.

\subsubsection{Thermodynamic Analysis}

Change in the values of entropy $\left(\Delta \mathrm{S}^{\circ}\right)$, Gibbs free energy $\left(\Delta \mathrm{G}^{\circ}\right)$ and enthalpy $\left(\Delta \mathrm{H}^{\circ}\right)$, were usually calculated to evaluate the thermodynamic direction and the behavior of adsorption process. The values of $\Delta \mathrm{H}^{\circ}$ and $\Delta \mathrm{S}^{\circ}$ can be calculated by means of Van't Hoff equation. Therefore, $\Delta \mathrm{G}^{\circ}$ can be obtained by the following Equations (8)-(10) [21]:

$$
\begin{gathered}
\Delta G^{\circ}=-R T \ln _{K_{d}}=-R T \ln b \\
\ln b=\frac{\Delta S^{\circ}}{R}-\frac{\Delta H^{\circ}}{R T} \\
b=q_{e}-C_{e}
\end{gathered}
$$


where $R$ presents the gas constant $(8.314 \mathrm{~J} /(\mathrm{mol} \cdot \mathrm{K})) ; T$ indicates the temperature value $(K)$; and $K_{d}$ is the thermodynamic equilibrium constant of adsorption process, $b$ presents the Langmuir equilibrium constant $(\mathrm{L} / \mathrm{mol})$.

\subsubsection{Conditional Factor Experiments}

The effect of lanthanum/chitosan (La/CS) ratio on the adsorption of phosphate was examined in a $20 \mathrm{mg} \cdot \mathrm{L}^{-1} \mathrm{~K}_{2} \mathrm{HPO}_{4}$ solution. La-chitosan ratios of $0.5,1.0,1.5,3.0$, and $5.0 \mathrm{mmol} / \mathrm{g}$ of La-chitosan magnetic spheres were added to the solution, respectively. The effect of dosage of La-chitosan magnetic spheres on the adsorption was examined in a $20 \mathrm{mg} \cdot \mathrm{L}^{-1} \mathrm{~K}_{2} \mathrm{HPO}_{4}$ solution. A certain amount of La-chitosan magnetic spheres was added to the solution so that the concentrations of the La-chitosan magnetic spheres were $0.5,1.0,1.5 \mathrm{~g} \cdot \mathrm{L}^{-1}$, respectively. The effect of $\mathrm{pH}$ on the sorption of phosphate by the La-chitosan magnetic spheres was examined in a $20 \mathrm{mg} \cdot \mathrm{L}^{-1} \mathrm{~K}_{2} \mathrm{HPO}_{4}$ solution at $\mathrm{pH}(3.0,5.0$, 7.0, 9.0), which was adjusted by using $0.1 \mathrm{M}$ hydrochloric acid or $0.1 \mathrm{M}$ sodium hydroxide solution. The effect of coexisting anions on the adsorption was examined by adding $0.05 \mathrm{~g}$ of La-chitosan magnetic spheres into the solution containing $0.1 \mathrm{M}$ co-existing anions, which were prepared by dissolving sodium salts of $\mathrm{Cl}^{-}, \mathrm{NO}_{3}{ }^{-}$, and $\mathrm{CO}_{3}{ }^{2-}$ into $20 \mathrm{mg} \cdot \mathrm{L}^{-1} \mathrm{~K}_{2} \mathrm{HPO}_{4}$ solution. Except for studying the effect of $\mathrm{pH}$ value on adsorption capacity, the other adsorption studies were performed at a $\mathrm{pH}$ of 7.0 .

\section{Results and Discussion}

\subsection{Characterization}

\subsubsection{SEM Analysis}

Figure 1 presents the SEM images and energy dispersive spectrum (EDS) diagrams of the chitosan magnetic spheres and La-chitosan magnetic spheres. The samples both exhibit a typical uniform and regular porous structure with $15 \mu \mathrm{m}$ of pore size (Figure 1a,d). More vividly, the structure of as-prepared spheres is similar to honeycomb-like shape, which is similar to what is reported in the literature [22]. In addition, the surface of La-chitosan magnetic spheres seems rougher and presents an arc sheet shape (Figure 1b,e). And it's obvious and intuitive that the lamellar surface of La-chitosan magnetic spheres is uniformly covered with a mesh of rod-like particles (Figure 1b,e), which is more favorable for adsorption of phosphate. As can be seen from the EDS diagrams in Figure 1c,f, it's clear that lanthanum elements could be clearly observed and contained inside the La-chitosan magnetic spheres compared to the chitosan magnetic spheres. 

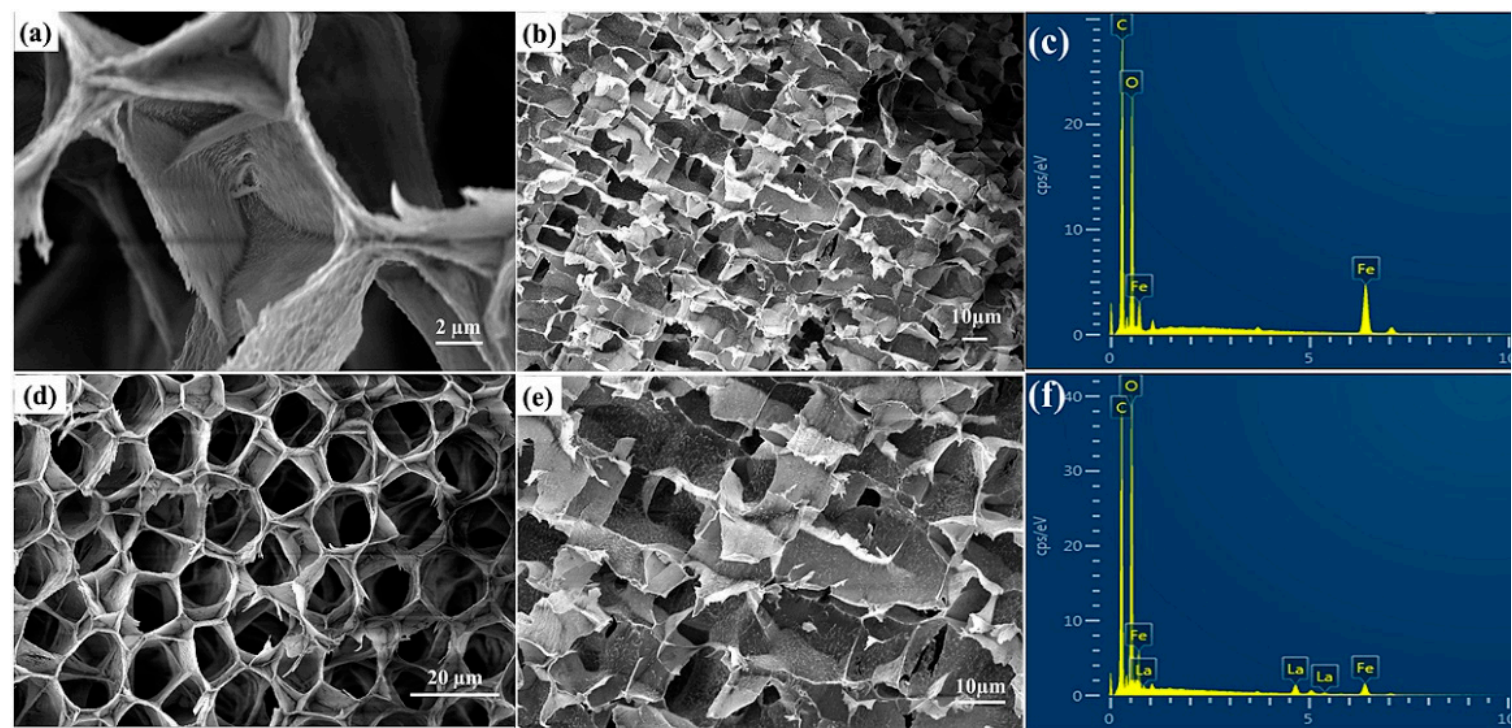

Figure 1. SEM images and EDS diagrams of the as-prepared chitosan magnetic spheres (a-c) and La-chitosan magnetic spheres (d-f).

\subsubsection{VSM Analysis}

The magnetization curves of La-chitosan magnetic spheres from the analysis of a vibrating sample magnetometer (VSM) at room temperature is shown in Figure 2. It can be seen that the saturation magnetization intensity of La-chitosan magnetic spheres is $7.90 \mathrm{emu} / \mathrm{g}$. Meanwhile, as shown in the inset photo of Figure 2, with a magnet placed at the bottom of the bottle, the adsorbents that originally floated on the surface of the water would quickly sink to the bottom within $2 \mathrm{~s}$, which intuitively shows the good magnetic properties and completely achieves solid-liquid separation for recovery and reuse from the treated solution.

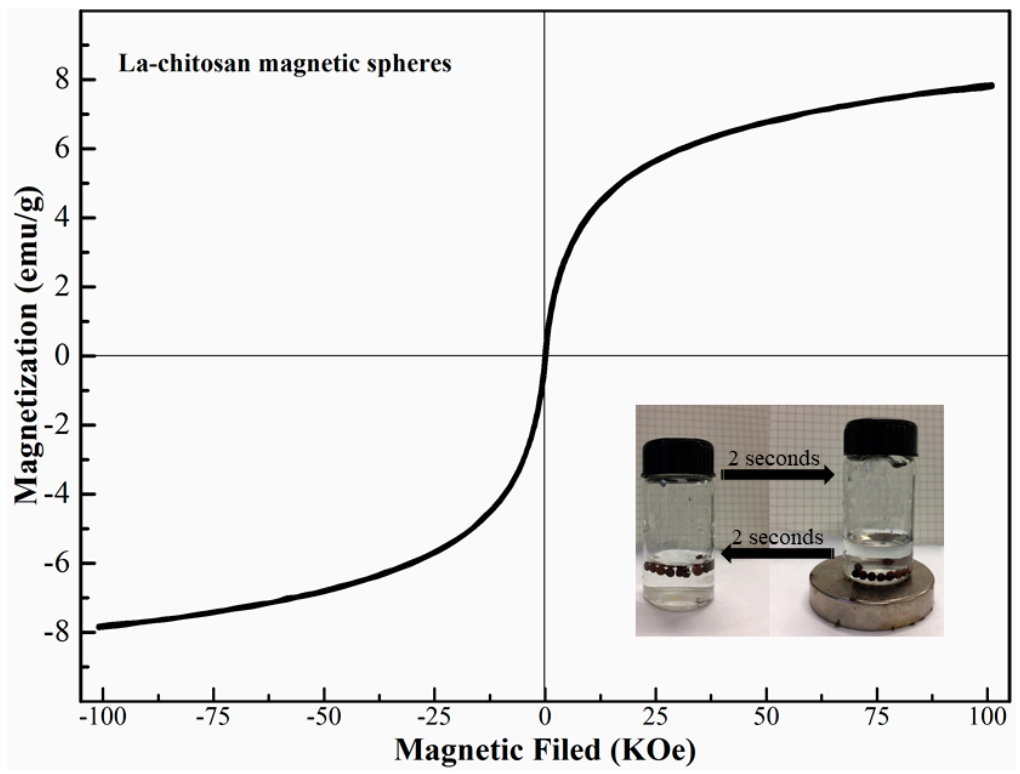

Figure 2. The magnetization curves of La-chitosan magnetic spheres (inserted with separationredispersion process).

\subsubsection{X-ray Diffraction Analysis}

XRD results of the chitosan magnetic spheres and La-chitosan magnetic spheres are shown in Figure 3. It could be seen that there were three obvious characteristic peaks at $20^{\circ}, 33.3^{\circ}$, and $43^{\circ}$, 
corresponding to the (110), (220), and (400) crystal plane positions of FeOOH of which hydroxyl groups are coordination groups and have better adsorption effects on phosphate ions. In addition, two obvious characteristic peaks at $35^{\circ}$, and $62.5^{\circ}$ were presented, which certifies the existence of $\mathrm{Fe}_{3} \mathrm{O}_{4}$. Based on the above, the main forms of the metal compounds in chitosan magnetic spheres are $\mathrm{FeOOH}$ and $\mathrm{Fe}_{3} \mathrm{O}_{4}$. From the XRD pattern in red curve, it's found that the distinct characteristic peaks at $28^{\circ}, 43^{\circ}$ and $58^{\circ}$ corresponded with (222), (431) and (541) crystal plane positions of lanthanum oxide. Thus, the Fe and La elements in the La-magnetic chitosan spheres were mainly present in the form of $\mathrm{Fe}_{3} \mathrm{O}_{4}, \mathrm{FeOOH}$, and $\mathrm{La}_{2} \mathrm{O}_{3}$, which are consistent with the weak magnetism of the material (Figure 2). Moreover, the presence of $\mathrm{La}_{2} \mathrm{O}_{3}$ (marked blue peaks in Figure 3) is also a key factor that increased the adsorption capacity of phosphate on the adsorbent.

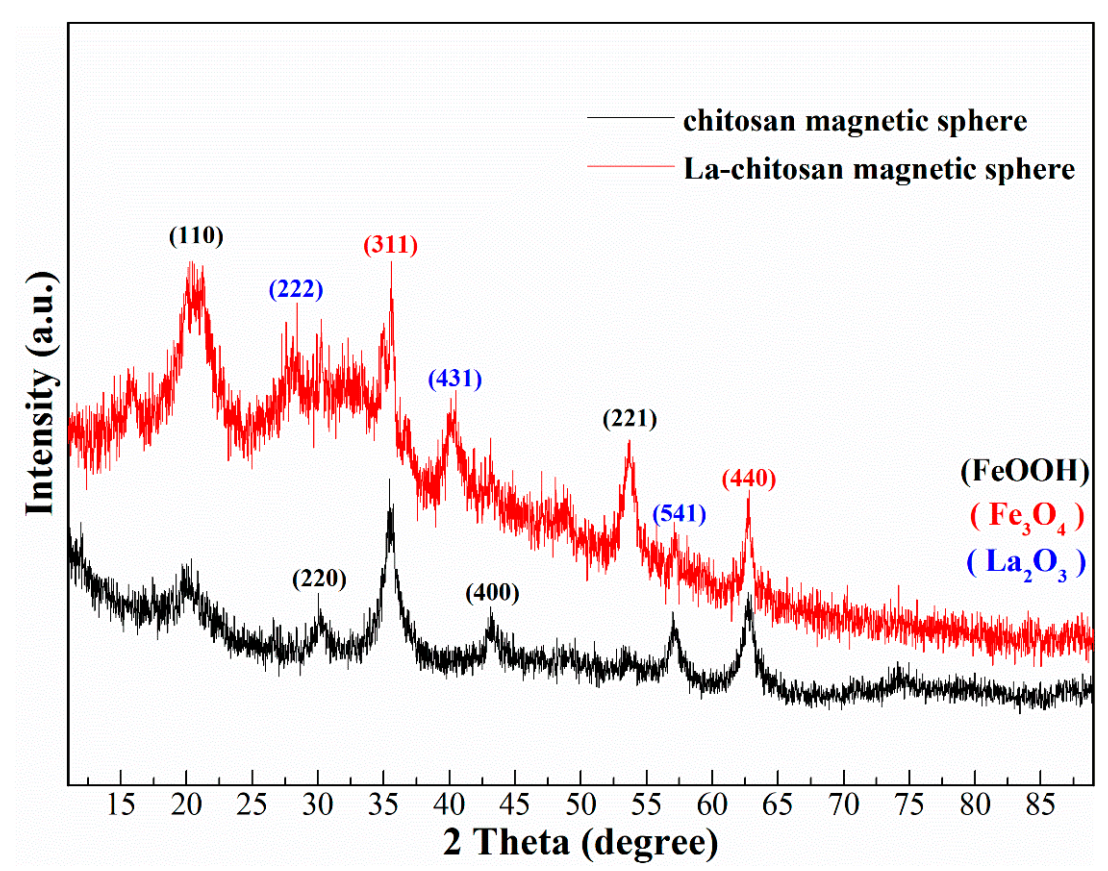

Figure 3. XRD spectra of chitosan magnetic spheres and La-chitosan magnetic spheres.

\subsubsection{FTIR Analysis}

Figure 4 shows the FTIR spectra of chitosan magnetic spheres and La-chitosan magnetic spheres before and after the reaction. The peak at $3435 \mathrm{~cm}^{-1}$ of the chitosan magnetic spheres represents the stretching vibration peak of $-\mathrm{NH} /-\mathrm{OH}$. The characteristic absorption peak of $-\mathrm{CH}$ and $-\mathrm{CH}_{2}$ derived from chitosan is located at $2915 \mathrm{~cm}^{-1}$. The peak at $570 \mathrm{~cm}^{-1}$ shows the $\mathrm{Fe}-\mathrm{O}$ vibration peak of $\mathrm{Fe}_{3} \mathrm{O}_{4}$, which is consistent with the results of XRD spectrogram (Figure 3). Compared with the chitosan magnetic spheres, the bending vibration strength of the $\mathrm{N}-\mathrm{H}$ is much larger before the reaction, which may be due to the bending of the $\mathrm{N}-\mathrm{H}$ after the $\mathrm{La}^{3+}$ coordinates with the nitrogen atom of the chitosan to increase steric hindrance. C-O stretching vibration peak moves from $1029 \mathrm{~cm}^{-1}$ to $1031 \mathrm{~cm}^{-1}$, and the intensity increases, probably because $\mathrm{La}^{3+}$ coordinates with hydroxyl oxygen atoms of chitosan afterwards, the electron density of the oxygen atoms was reduced, and $\mathrm{C}-\mathrm{O}$ bond was weakened. The vibration peak of Fe-O is shifted to $626 \mathrm{~cm}^{-1}$. Combined with XRD analysis, it is presumably due to the formation of FeOOH. Compared with the results before the reaction, the peak at $1432 \mathrm{~cm}^{-1}$ of La-chitosan magnetic spheres almost disappeared and moved to $1381 \mathrm{~cm}^{-1}$ after the reaction, indicating that hydroxyl was involved in the adsorption process of phosphates. 


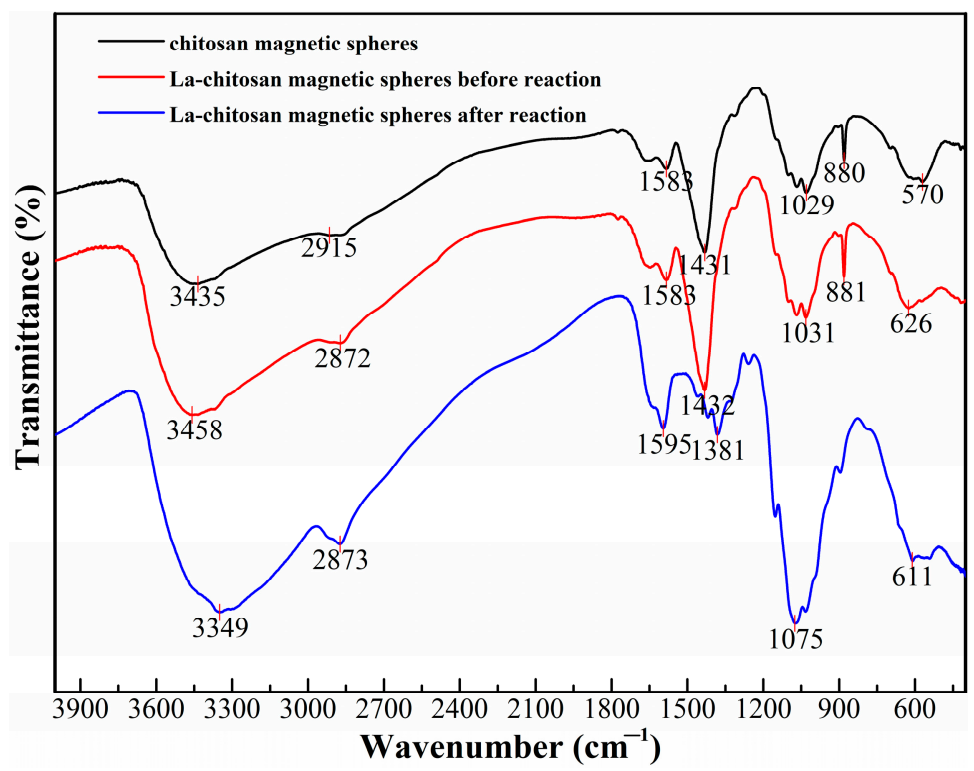

Figure 4. FTIR spectra of chitosan magnetic spheres and La-chitosan magnetic spheres before and after reaction.

\subsection{Adsorption Experiments}

\subsubsection{Adsorption Kinetics}

As shown in Figure 5a, the adsorption capacity was rapidly increased during the initial $5 \mathrm{~h}$, reaching more than $80 \%$ of the saturated adsorption amount. However, as time further increased, the increase of adsorption slowed down due to the augment of the available adsorption sites on the surface of the adsorbent. After $5 \mathrm{~h}$, the adsorption went into a more gradual phase, achieving adsorption equilibrium within $10 \mathrm{~h}$.

For the further investigation of the phosphate adsorption process by La-chitosan magnetic spheres, both of the pseudo-first-order and pseudo-second-order models are used to the processing of kinetic data recorded in Figure 5a, as shown in Figure 5b,c. Meanwhile, the corresponding parameters and correlation coefficients obtained by fitting means are clearly presented in Table 1 . Compared with the pseudo-first-order model (coefficient of determination $\left(R^{2}\right)=0.97$ ), the pseudo-second-order model $\left(\mathrm{R}^{2}=0.99\right)$ can better depict and explicate the adsorption process, indicating that the chemisorption or chemical bonding between active sites of La-chitosan magnetic spheres and phosphate might play a leading role in the adsorption process.

As is shown in Figure 5d, the linear trend of intra-particle diffusion model clearly presents a three-stage type, which indicates that the adsorption process of as-prepared adsorbents consists of several stages [23]. The first region (the black line in Figure $5 \mathrm{~d}$ ) is mainly facilitated by the external surface or instantaneous adsorption. The main driving force in the first region is the concentration differences of phosphate. The gradual adsorption stage is presented by the second linear portion as shown in the red line in Figure 5d. Meanwhile, it is seen that the gradual adsorption stage is the rate-limiting step. There is no doubt that the third line segment (blue line in Figure 5d) is the final equilibrium stage. The deceleration of above stage is put down to the low content of residual phosphate in solution. 

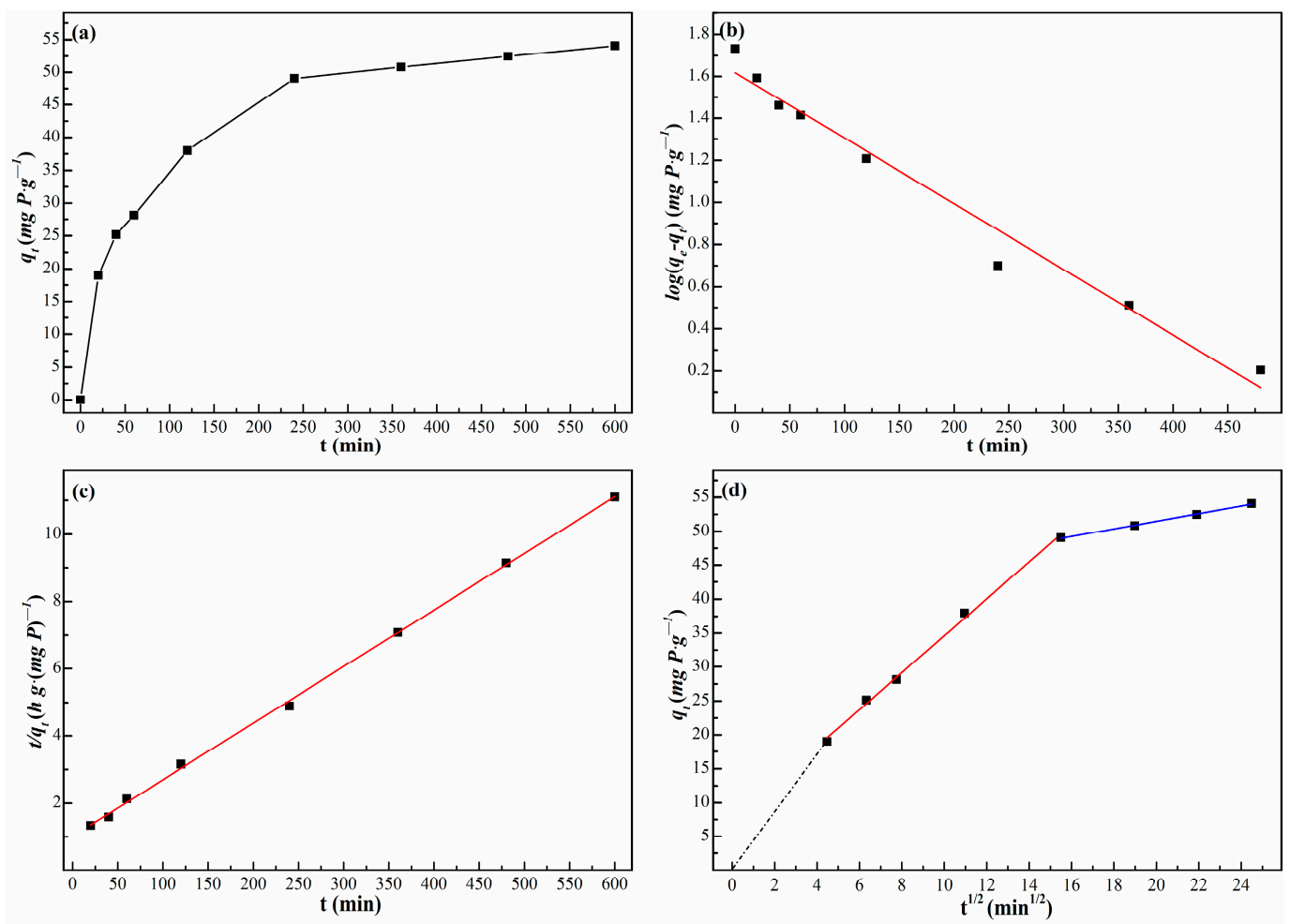

Figure 5. (a) Effect of contact time on the adsorption capacity of La-chitosan magnetic spheres, (b) pseudo-first-order model, (c) pseudo-second-order model, and (d) intra-particle diffusion model.

Table 1. Adsorption kinetic parameters of phosphorus onto La-chitosan magnetic spheres.

\begin{tabular}{|c|c|c|c|c|c|c|c|c|c|c|}
\hline \multirow[b]{2}{*}{$\begin{array}{c}C_{0} \\
\left(\mathrm{mg} \cdot \mathrm{L}^{-1}\right)\end{array}$} & \multirow[b]{2}{*}{$\begin{array}{c}q_{e, e x p} \\
\left(\mathrm{mg} \mathrm{g}^{-1}\right)\end{array}$} & \multicolumn{3}{|c|}{ Pseudo-First-Order } & \multicolumn{3}{|c|}{ Pseudo-Second-Order } & \multicolumn{3}{|c|}{ Intra-Particle Diffusion } \\
\hline & & $\begin{array}{c}q_{e, c a l} \\
\left(\mathrm{mg} \mathrm{g}^{-1}\right)\end{array}$ & $\begin{array}{c}k_{1} \\
\left(\min ^{-1}\right)\end{array}$ & $\mathbf{R}^{2}$ & $\begin{array}{c}q_{e, c a l} \\
\left(\mathrm{mg} \mathrm{g}^{-1}\right)\end{array}$ & $\stackrel{k_{2}}{\left(\mathrm{~g} \mathrm{mg}^{-1} \min ^{-1}\right)}$ & $\mathbf{R}^{2}$ & $\begin{array}{c}k_{\mathrm{p} 1} \\
\left(\mathrm{~g} \mathrm{mg}^{-1} \min ^{-1}\right)\end{array}$ & $\begin{array}{c}k_{\mathrm{p} 2} \\
\left(\mathrm{~g} \mathrm{mg}^{-1} \min ^{-1}\right)\end{array}$ & $\mathbf{R}^{2}$ \\
\hline 20 & 54.08 & 41.69 & 0.01 & 0.97 & 59.52 & 0.02 & 0.99 & 2.72 & 0.56 & 0.97 \\
\hline
\end{tabular}

\subsubsection{Adsorption Isotherm}

As shown in Figure 6, Langmuir (a) and Freundlich (b) isotherm models were used to evaluate the adsorption isotherms of phosphate by La-chitosan magnetic spheres. Meanwhile, the estimated model parameters with the coefficient of determination $\left(R^{2}\right)$ for the different models are shown in Table 2 . The coefficient of determination, $R^{2}$, given in the Table 2 , shows that the both Freundlich and Langmuir isotherm models can be used to explain the adsorption isotherms of La-chitosan magnetic spheres well. In the cases of $\mathrm{R}^{2}$ values, the applicability of the above models, based on current experimental data, follows the order: Langmuir > Freundlich. Clearly, The $\mathrm{R}^{2}$ values obtained for the Freundlich and Langmuir models were both above 0.98 , indicating that both monolayer adsorption and multilayer adsorption occur in the system as shown in Figure 6. Results similar to those in this paper have been reported for the adsorption of phosphate in other literature [24]. According to the Langmuir model, the maximum phosphorus adsorption capacity reached $27.78 \mathrm{mg} \mathrm{P.g}{ }^{-1}$. Moreover, $R_{L}$ values $(0.0379)$ fall within the range of $0-1.0$, implying that the phosphate adsorption onto La-chitosan magnetic spheres is favorable. 

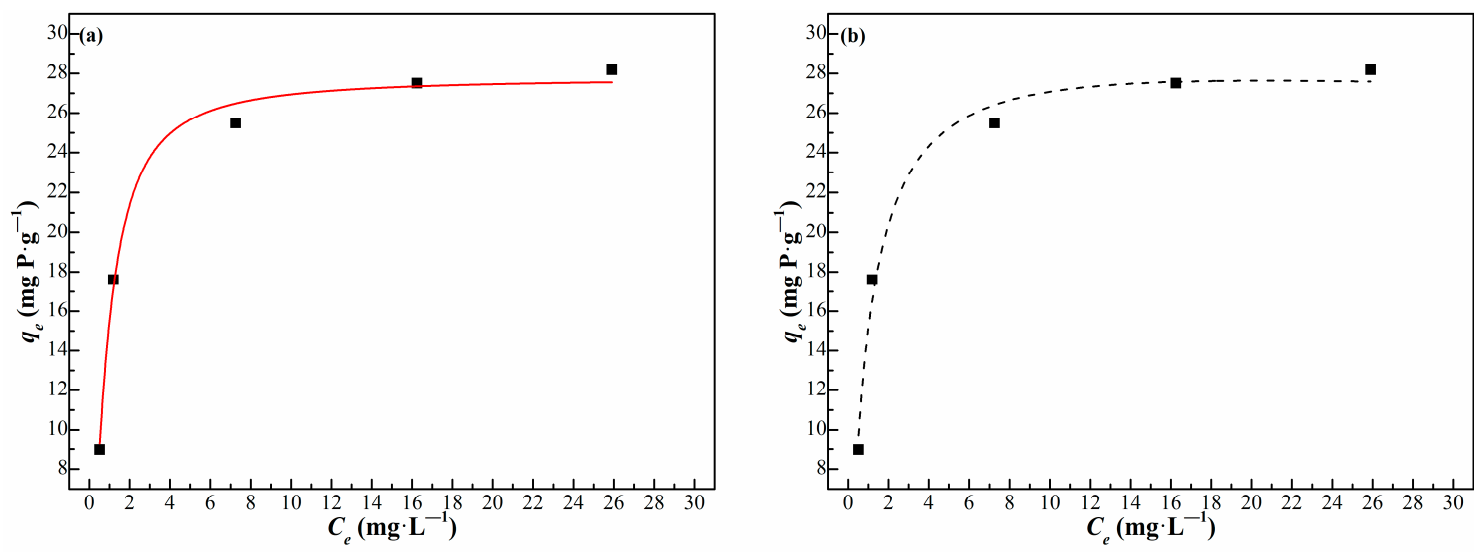

Figure 6. Langmuir (a) and Freundlich (b) models for the isotherm adsorption experiment.

Table 2. Adsorption isotherm parameter fitting result of Langmuir and Freundlich model.

\begin{tabular}{cccccccc}
\hline \multirow{2}{*}{ Adsorbents } & \multicolumn{3}{c}{ Langmuir Model } & \multicolumn{3}{c}{ Freundlich Model } \\
\cline { 2 - 8 } & $\begin{array}{c}\boldsymbol{q}_{\text {max }} \\
\left(\mathbf{m g ~ P}^{-1} \mathbf{g}^{-\mathbf{1}}\right)\end{array}$ & $\begin{array}{c}\boldsymbol{K}_{\mathbf{L}} \\
\left(\mathbf{L} \cdot \mathbf{~ m g ~}^{-\mathbf{1}}\right)\end{array}$ & $\boldsymbol{R}_{\mathbf{L}}$ & $\mathbf{R}^{\mathbf{2}}$ & $\boldsymbol{K}_{\boldsymbol{F}}$ & $\mathbf{1 / n}$ & $\mathbf{R}^{\mathbf{2}}$ \\
\hline La-chitosan magnetic spheres & 27.78 & 1.27 & 0.0379 & 0.99 & 15.16 & 0.54 & 0.98 \\
\hline
\end{tabular}

\subsubsection{Thermodynamic Analysis}

As we all known, the spontaneous nature of the processes is usually judged by three valuable thermodynamic parameters $\left(\Delta \mathrm{G}^{\circ}, \Delta \mathrm{S}^{\circ}\right.$, and $\left.\Delta \mathrm{H}^{\circ}\right)$. Generally, values of $\Delta \mathrm{G}^{\circ}$ in the range of -20 to $0 \mathrm{~kJ} / \mathrm{mol}$ presents a physical adsorption process; while $\Delta \mathrm{G}^{\circ}$ values in range of -80 to $-400 \mathrm{~kJ} / \mathrm{mol}$ presents a process of chemical adsorption [25]. Figure 7 shows the linear diagram of $\ln \left(q_{e} / C_{e}\right)$ (vertical ordinate) vs. $1 / \mathrm{T}$ (horizontal ordinate). The calculated corresponding parameter values are listed in Table 3. As shown in Table 3, the $\Delta G^{\circ}$ values are less than zero at all temperatures, which means that the adsorption of phosphate onto La-chitosan magnetic spheres is favorable and spontaneous behavior. Moreover, the value of $\Delta \mathrm{G}^{\circ}$ is increased gradually from $-32.04 \mathrm{~kJ} / \mathrm{mol}$ to $-26.88 \mathrm{~kJ} / \mathrm{mol}$ with the alteration of temperature from $25{ }^{\circ} \mathrm{C}$ to $45^{\circ} \mathrm{C}$, illustrating that the spontaneity of this adsorption process is declined at elevated temperature. From Table 3, it is obvious that values of $\Delta \mathrm{G}^{\circ}$ are neither in the ranges of $\Delta \mathrm{G}^{\circ}$ in physical adsorption nor chemical adsorption process. Relatively speaking, the values of $\Delta \mathrm{G}^{\circ}$ are closer to the process of physical adsorption. The possible explanation is that with the exception of physical adsorption, many other mechanisms may work together, such as electrostatic interaction and ligand exchange [26]. In Table 3, the negative value of $\Delta \mathrm{H}^{\circ}(-77.73 \mathrm{KJ} / \mathrm{mol})$ confirms the exothermic nature of phosphate adsorption [27]. In addition, The negative value of $\Delta \mathrm{S}^{\circ}$ $(-0.1615 \mathrm{KJ} /(\mathrm{mol} \cdot \mathrm{K}))$ definitely illuminates the decline in randomness during the adsorption process.

Table 3. Thermodynamic parameters for phosphate adsorption on La-chitosan magnetic spheres at $15^{\circ} \mathrm{C}, 25^{\circ} \mathrm{C}, 35^{\circ} \mathrm{C}$, and $45^{\circ} \mathrm{C}$, respectively.

\begin{tabular}{ccccc}
\hline Temperature $\left({ }^{\circ} \mathbf{C}\right)$ & $\mathbf{b}(\mathrm{L} / \mathbf{m o l})$ & $\Delta \mathbf{G}^{\circ}(\mathrm{KJ} / \mathbf{m o l})$ & $\Delta \mathbf{S}^{\circ}(\mathrm{KJ} /(\mathbf{m o l} \cdot \mathbf{K}))$ & $\Delta \mathbf{H}^{\circ}(\mathrm{KJ} / \mathbf{m o l})$ \\
\hline 15 & 646,695 & -32.04 & & \\
25 & 90,932 & -8.29 & -0.1615 & -77.73 \\
35 & 55,181 & -27.96 & & \\
45 & 26,061 & -26.88 & & \\
\hline
\end{tabular}




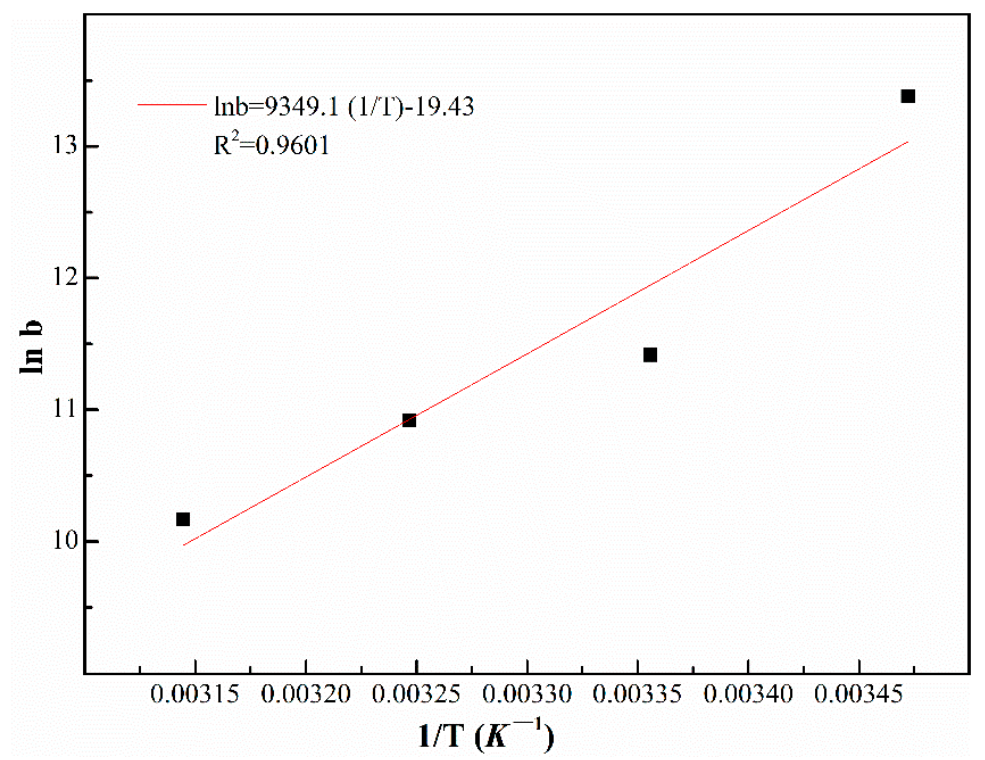

Figure 7. Van't Hoff diagram for the adsorption of phosphate with La-chitosan magnetic spheres.

Table 4 shows the concrete comparison of phosphate adsorption capacity of different reported adsorbents, which showed that La-chitosan magnetic spheres had higher adsorption capacity for phosphate compared to other adsorbents reported. Moreover, the adsorption capacity of La-chitosan magnetic spheres is obviously higher than that of commercial Phoslock ${ }^{\circledR}$.

Table 4. The comparison of phosphate adsorption capacity of different adsorbents.

\begin{tabular}{cccc}
\hline Type of Adsorbents & $\boldsymbol{q}_{\boldsymbol{m}} \mathbf{( \mathbf { m g ~ P } \cdot \mathbf { g } ^ { - \mathbf { 1 } } )}$ & Isotherm Model & Reference \\
\hline La-chitosan magnetic spheres $\mathrm{Fe}_{3} \mathrm{O}_{4} @ \mathrm{SiO}_{2}$ with $\mathrm{La}_{2} \mathrm{O}_{3}$ & 27.78 & Langmuir & This work \\
Phoslock ${ }^{\circledR}$ (lanthanum-modified bentonite) & 27.8 & Langmuir & {$[14]$} \\
NT-25La & $9.5-10.5$ & Langmuir & {$[25]$} \\
Activated aluminium oxide & 14.0 & Langmuir & {$[28]$} \\
Fe (III)-modified bentonite & 13.8 & Langmuir & {$[29]$} \\
$\mathrm{Al}$ (III)-modified bentonite & 11.2 & Langmuir & {$[30]$} \\
\hline
\end{tabular}

\subsubsection{Effect of La/CS Ratios}

Figure 8 shows the adsorption efficiency of the La-chitosan magnetic spheres with different $\mathrm{La} / \mathrm{CS}$ ratios. It is obvious that the adsorption capacity of chitosan magnetic spheres reached only $10 \mathrm{mg} \mathrm{P} \cdot \mathrm{g}^{-1}$, while the adsorption capacity of La-chitosan magnetic spheres generally increased with the change of $\mathrm{La} / \mathrm{CS}$ ratio. In addition, it can be seen that the optimal $\mathrm{La} / \mathrm{CS}$ ratio is $1.0 \mathrm{mmol} / \mathrm{g}$, and the adsorption capacity reaches $27.49 \mathrm{mg} \mathrm{P} \cdot \mathrm{g}^{-1}$. We can find that the fluctuation of adsorption capacity was occurred during the first 1.0-3.0 h. The reason for this phenomenon may be due to the freeze-drying process in the preparation of materials. When the adsorbent is just in contact with the phosphorus solution at the beginning, it adsorbed a large amount of phosphorus solution, resulting in a sudden increase in the amount of adsorption. When the adsorbent is moist enough, part of the solution will overflow, resulting in a slight decrease in the amount of adsorption. It is worth pointing out that the irregular changes of adsorption capacity of phosphate in water were showed in the first $1.0 \mathrm{~h}$ due to the incipient wetting process of freeze-dried materials. Thus, with the completion of wetting process, the amount of phosphate adsorbed in water gradually increased, as shown in Figure 8.

When the material is added to the water, the following steps may occur: the particle wetting process (first 1.0-3.0 h), rapid adsorption process (3-10 h), and adsorption saturation process (10-20 h). As a whole, with the augment of La/chitosan ratio, the corresponding adsorption capacity gradually 
increased. The ultimate adsorption capacity $\left(27.49 \mathrm{mg} \mathrm{P} \cdot \mathrm{g}^{-1}\right)$ was gained when the La/chitosan ratio is equal to $1.0 \mathrm{mmol} / \mathrm{g}$. When the dosage is less than the maximum value, the adsorption capacity will increase with the increase of the dosage. And when the dosage is greater than the maximum, the adsorption capacity is still equal to the maximum value. This is because the pore size, specific surface area, and shape of the adsorbents are affected when too much lanthanum is added. Meanwhile, the optimal ratio was selected in the subsequent experiments.

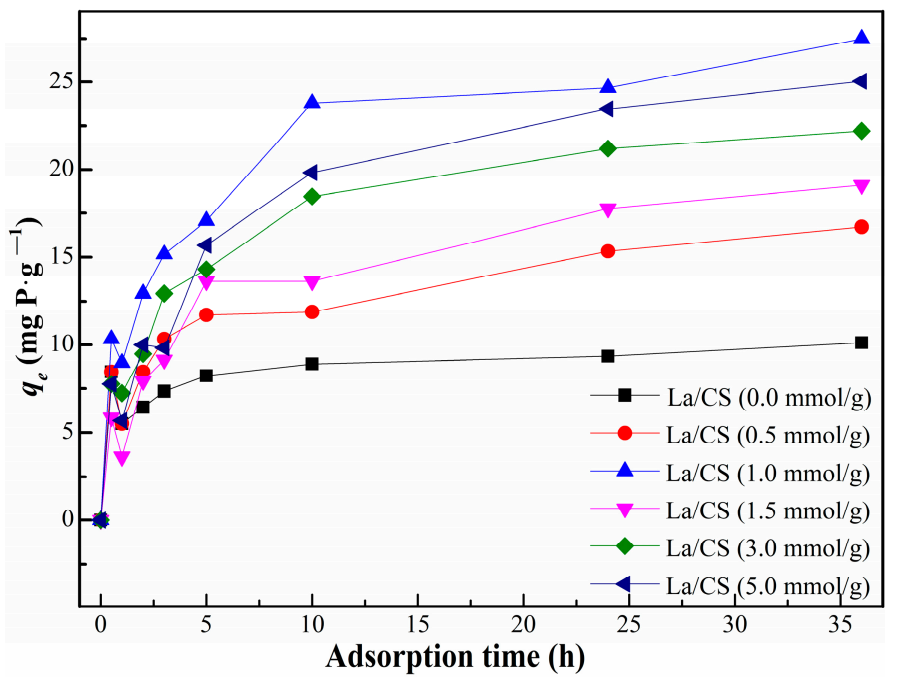

Figure 8. Effect of La/CS ratios on phosphate adsorption capacity of La-chitosan magnetic spheres.

\subsubsection{The Effect of Dosage}

Figure 9 shows the adsorption efficiency of different dosages of La-chitosan magnetic spheres. We can clearly see that when lanthanum was doped into magnetic spheres, the adsorption capacity increased by $23.6 \%$ compared with the chitosan magnetic spheres. Meanwhile, the adsorption capacity increased significantly to $33.1 \mathrm{mg} \mathrm{P} \cdot \mathrm{g}^{-1}, 40.9 \mathrm{mg} \mathrm{P} \cdot \mathrm{g}^{-1}, 51.3 \mathrm{mg} \mathrm{P} \cdot \mathrm{g}^{-1}$, and $54.7 \mathrm{mg} \mathrm{P} \cdot \mathrm{g}^{-1}$, respectively, with the dosage of adsorbents generally increased. Along with the enhancement of adsorbent dosage, the adsorption activity points increased, leading to more phosphate being adsorbed. It is worth mentioning that the addition in as-prepared spheres may increase the cost of preparation, while the adsorption capacity of La-chitosan magnetic spheres increases by $21.6 \%$. The cost of composite materials is further reduced indirectly because of the recoverability and reusability of magnetic spheres.

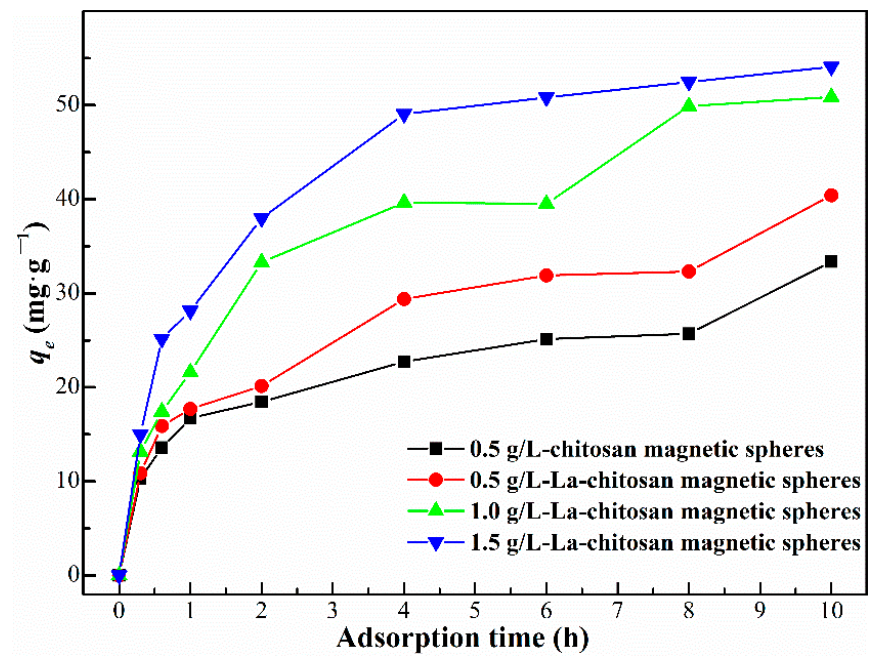

Figure 9. Effect of dosage of La-chitosan magnetic spheres on the phosphate adsorption capacity. 


\subsubsection{The Effect of $\mathrm{pH}$}

In general, $\mathrm{pH}$ of the aqueous solution affects the existing state of the substance in the solution and the surface charge is usually considered as a vital and meaningful variable that interferes with the adsorption of ions at water-adsorbent interfaces in the adsorption process. The adsorption of phosphate on La-chitosan magnetic spheres were studied at various $\mathrm{pH}$ values ranging from 3.0 to 9.0, as shown in Figure 10. When the $\mathrm{pH}$ value is 3.0, the adsorbent capacity of La-chitosan magnetic spheres reaches the maximum equilibrium adsorption and is significantly higher than that under the other $\mathrm{pH}$ conditions. When the $\mathrm{pH}$ value increased from 3.0 to 9.0, the adsorption capacity gradually decreased. On the one hand, the surface of the adsorbent will carry more negative charges at higher $\mathrm{pH}$ value, making it reject negatively charged ions in the solution. In the alkaline solution, the competitive relation adsorption active center of adsorbents between the phosphate ions and $\mathrm{OH}^{-}$ions was significantly enhanced and resulted in a significant decrease in the capacity of phosphate. On the other hand, when the $\mathrm{pH}$ of the solution is greater than the point of zero charge, the common ion repulsion or electrostatic repulsion force is dominant. In addition, phosphate acid exists as four different chemical forms $\left(\mathrm{H}_{3} \mathrm{PO}_{4}, \mathrm{H}_{2} \mathrm{PO}_{4}{ }^{-}, \mathrm{HPO}_{4}{ }^{2-}\right.$, and $\left.\mathrm{PO}_{4}{ }^{3-}\right)$ at different $\mathrm{pH}$ ranges $\left(\mathrm{H}_{3} \mathrm{PO}_{4} \leftrightarrow \mathrm{H}_{2} \mathrm{PO}_{4}{ }^{-}+\mathrm{H}^{+}\left(\mathrm{pK}_{\mathrm{a} 1}\right) ; \mathrm{H}_{2} \mathrm{PO}_{4}{ }^{-} \leftrightarrow \mathrm{HPO}_{4}{ }^{2-}+\mathrm{H}^{+}\left(\mathrm{pK}_{\mathrm{a} 2}\right) ; \mathrm{HPO}_{4}{ }^{2-} \leftrightarrow \mathrm{PO}_{4}{ }^{3-}+\mathrm{H}^{+}\left(\mathrm{pK}_{\mathrm{a} 3}\right)\right)$. The dissociation constants for above three reactions are $\mathrm{pK}_{\mathrm{a} 1}=2.15, \mathrm{pK}_{\mathrm{a} 2}=7.20$ and $\mathrm{pK}_{\mathrm{a} 3}=12.33$, respectively [31]. When the $\mathrm{pH}$ of solution is between 2.15 and 7.20, the phosphate acid exists mainly in the form of $\mathrm{H}_{2} \mathrm{PO}_{4}^{-}$, which is the greatest affinity for the La-chitosan magnetic spheres to form $\mathrm{La}(\mathrm{OH})_{2}{ }^{+}$. As a result, the adsorbent has a large adsorption capacity, which is basically consistent with the experimental results (Figure 10).

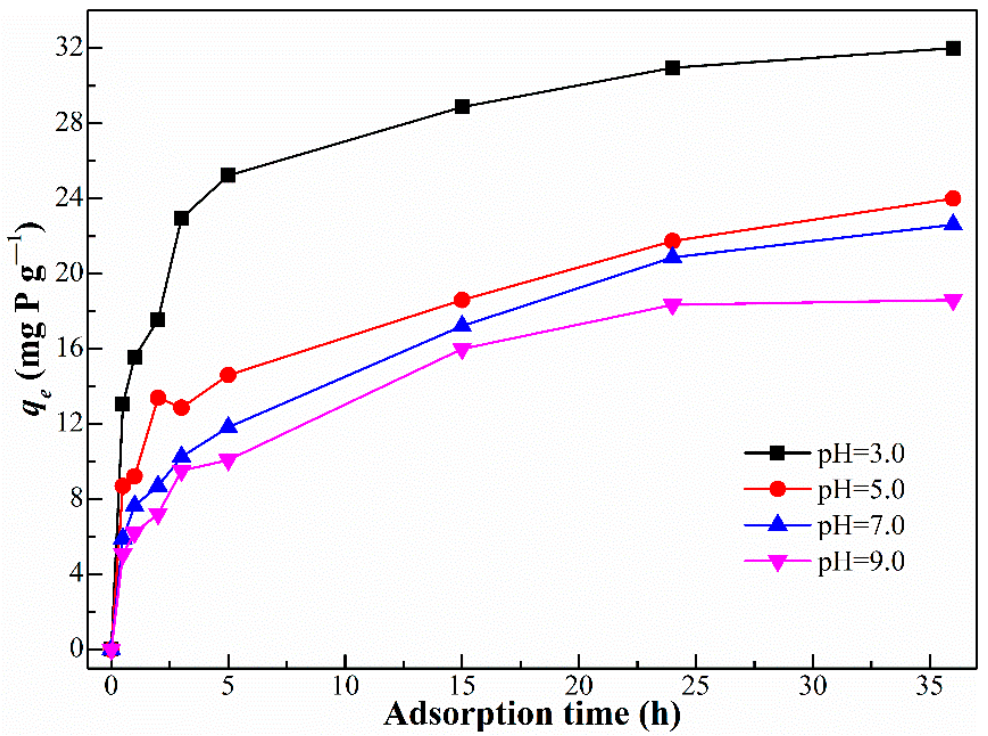

Figure 10. Effect of $\mathrm{pH}$ on the adsorption capacity of the La-chitosan magnetic spheres.

\subsubsection{The Effect of Coexisting Anions}

Several anions such as $\mathrm{CO}_{3}{ }^{2-}, \mathrm{Cl}^{-}$, and $\mathrm{NO}_{3}{ }^{-}$are common in natural freshwater, and could participate in the phosphate adsorption process by means of competition of adsorption sites of adsorbents. Figure 11 obviously shows the effect of coexisting ions including $\mathrm{CO}_{3}{ }^{2-}, \mathrm{Cl}^{-}$, and $\mathrm{NO}_{3}{ }^{-}$ $\left(0.1 \mathrm{~mol} \cdot \mathrm{L}^{-1}\right)$ on the adsorption of La-chitosan magnetic spheres. It is clearly found that $\mathrm{Cl}^{-}$ (13.51 $\left.\mathrm{mg} \mathrm{P} \cdot \mathrm{g}^{-1}\right)$, and $\mathrm{NO}_{3}{ }^{-}\left(13.88 \mathrm{mg} \mathrm{P} \cdot \mathrm{g}^{-1}\right)$ has the slight/negligible influence on adsorption capacity

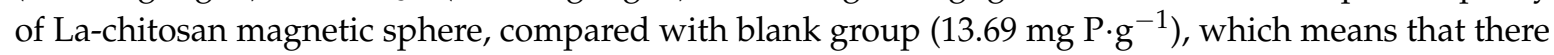
is almost no competitive adsorption between the above-mentioned ions $\left(0.1 \mathrm{~mol} \cdot \mathrm{L}^{-1} \mathrm{Cl}^{-}\right.$and $\left.\mathrm{NO}_{3}{ }^{-}\right)$ and the phosphate ions on La-chitosan magnetic spheres. However, $\mathrm{CO}_{3}{ }^{2-}\left(5.92 \mathrm{mg} \mathrm{P} \cdot \mathrm{g}^{-1}\right)$ has wielded the most significant influence, which could be attributed to the smaller solubility product constant 
$(\mathrm{Ksp})\left(3.98 \times 10^{-34}\right)$ of $\mathrm{La}_{2}\left(\mathrm{CO}_{3}\right)_{3}$ compared with the $\mathrm{Ksp}$ of $\mathrm{LaPO}_{4}\left(3.70 \times 10^{-23}\right)$. The competitive relationship for the adsorptive sites between co-existing $\mathrm{CO}_{3}{ }^{2-}$ and phosphate in solution is formed, then resulting into a sharp decrease in the phosphate adsorption capacity [31].

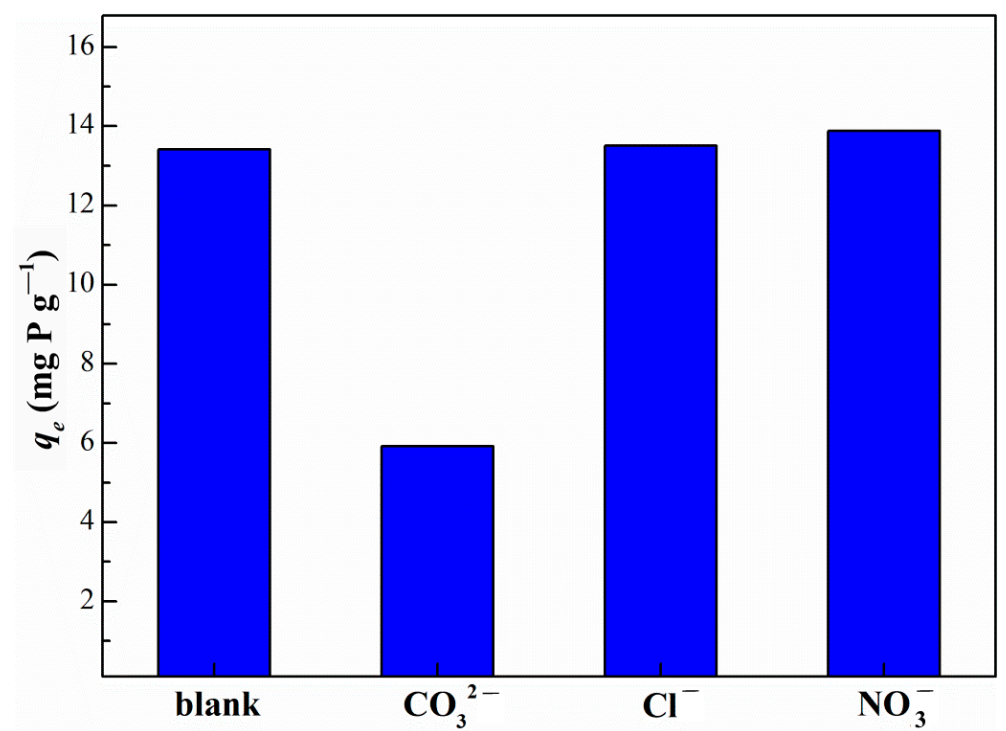

Figure 11. Effect of coexisting anions on the phosphate adsorption capacity of La-chitosan magnetic spheres.

\section{Conclusions}

In this paper, La-chitosan magnetic spheres were prepared and their adsorption performance for phosphates was studied. The prepared La-chitosan magnetic spheres adsorbents have many lamellar and regular porous structures with pore size of $15 \mu \mathrm{m}$. The main components of the adsorbents are $\mathrm{FeOOH}$ and $\mathrm{La}_{2} \mathrm{O}_{3}$, and the adsorption capacity of the La-chitosan magnetic spheres is obviously higher than that without lanthanum. La-chitosan magnetic spheres show a high adsorption rate for phosphate, and the adsorption process is in accordance with the pseudo-second order kinetic model and belongs to chemical adsorption, monolayer adsorption and electrostatic attraction, and ligand exchange from the values of $\Delta \mathrm{G}^{\circ}$ and the effect of $\mathrm{pH}$ on the adsorption capacity. In the lanthanum-doping process, both $-\mathrm{NH}_{2}$ and $-\mathrm{OH}$ participate in the coordination. The ratio of La-chitosan magnetic spheres has an effect on the adsorption of La-chitosan magnetic spheres. The results of conditional experiments show that the optimal La/CS ratio is $1.0 \mathrm{mmol} / \mathrm{g}$, of which the adsorption capacity is $27.49 \mathrm{mg} \mathrm{P.g} \mathrm{g}^{-1}$; the positive correlation between the dosage of adsorbents and the capacity of the adsorbents; the initial $\mathrm{pH}$ of the solution has a significant effect on the adsorption capacity of La-chitosan magnetic spheres adsorbents. With the increasing of $\mathrm{pH}$ value, the adsorption capacity will be decreased significantly. At $\mathrm{pH}$ of 3.0 , the maximum adsorption capacity is achieved, which is $33.04 \mathrm{mg} \mathrm{P} \cdot \mathrm{g}^{-1}$. When the concentration of coexisting ions is $0.1 \mathrm{~mol} \cdot \mathrm{L}^{-1}, \mathrm{CO}_{3}{ }^{2-}$ will markedly reduce the phosphate adsorption capacity of as-prepared adsorbents, while $\mathrm{Cl}^{-}$and $\mathrm{NO}_{3}{ }^{-}$have little effect. Owing to their unique hierarchical porous structures, high-adsorption capacity, La-chitosan magnetic spheres are potentially applicable in water treatment.

Author Contributions: Conceptualization: L.W. and L.-J.S.; methodology: L.W., L.S.; validation: L.-J.S., Y.-Y.Z., and L.W.; formal analysis: L.-J.S. and R.C.; investigation, literature search, study design: Y.-Y.Z.; data curation: L.-J.S.; data collection and data analysis: D.-Y.D.; figure design: R.C., L.-W.L.; writing-original draft preparation: L.-J.S. and L.-W.L.; writing-review and editing: R.C., X.Z; visualization and data interpretation: L.W.; supervision: L.S.

Funding: This research was funded by the Special Funds of the Construction of World-class Universities (Disciplines) and Guidance of Characteristic Developments for the Central Universities (Renmin University of China, 2018). 
Acknowledgments: Thank L.W. for the careful revision of this article. L.-J.S. especially wants to thank the great support from R.C. during studying.

Conflicts of Interest: The authors declare no conflict of interest.

\section{References}

1. Mahdavi, S.; Akhzari, D. The removal of phosphate from aqueous solutions using two nano-structures: Copper oxide and carbon tubes. Clean Technol. Environ. Policy 2016, 18, 817-827. [CrossRef]

2. Zhang, M.; Gao, B.; Yao, Y.; Xue, Y.; Inyang, M. Synthesis of porous MgO-biochar nanocomposites for removal of phosphate and nitrate from aqueous solutions. Chem. Eng. J. 2012, 210, 26-32. [CrossRef]

3. Tu, Y.; You, C. Phosphorus adsorption onto green synthesized nano-bimetal ferrites: Equilibrium, kinetic and thermodynamic investigation. Chem. Eng. J. 2014, 251, 285-292. [CrossRef]

4. Yang, J.; Zeng, Q.; Peng, L.; Lei, M.; Song, H.; Tie, B.; Gu, J. La-EDTA coated $\mathrm{Fe}_{3} \mathrm{O}_{4}$ nanomaterial: Preparation and application in removal of phosphate from water. J. Environ. Sci. 2013, 25, 413-418. [CrossRef]

5. Lürling, M.; Van, O.F. Controlling eutrophication by combined bloom precipitation and sediment phosphorus inactivation. Water Res. 2013, 47, 6527-6537. [CrossRef] [PubMed]

6. Jabari, P.; Munz, G.; Yuan, Q.; Oleszkiewicz, J.A. Free nitrous acid inhibition of biological phosphorus removal in integrated fixed-film activated sludge (IFAS) system. Chem. Eng. J. 2016, 287, 38-46. [CrossRef]

7. Zheng, X.; Pan, J.; Zhang, F.; Liu, E.; Shi, W.; Yan, Y. Fabrication of free-standing bio-template mesoporous hybrid film for high and selective phosphate removal. Chem. Eng. J. 2016, 284, 879-887. [CrossRef]

8. Dithmer, L.; Nielsen, U.G.; Lundberg, D.; Reitzel, K. Influence of dissolved organic carbon on the efficiency of P sequestration by a lanthanum modified clay. Water Res. 2016, 97, 39-46. [CrossRef] [PubMed]

9. Yao, Y.; Gao, B.; Inyang, M.; Zimmerman, A.R.; Cao, X.; Pullammanappallil, P.; Yang, L. Removal of phosphate from aqueous solution by biochar derived from anaerobically digested sugar beet tailings. J. Hazard. Mater. 2011, 190, 501-507. [CrossRef] [PubMed]

10. Zhang, X.; Sun, F.; He, J.; Xu, H.; Cui, F. Robust phosphate capture over inorganic adsorbents derived from lanthanum metal organic frameworks. Chem. Eng. J. 2017, 326, 1086-1094. [CrossRef]

11. Chen, L.; Zhao, X.; Pan, B.; Zhang, W.; Hua, M.; Lv, L.; Zhang, W. Preferable removal of phosphate from water using hydrous zirconium oxide-based nanocomposite of high stability. J. Hazard. Mater. 2015, 284, 35-42. [CrossRef] [PubMed]

12. Zhang, L.; Gao, Y.; Zhou, Q.; Kan, J.; Wang, Y. High-Performance Removal of Phosphate from Water by Graphene Nanosheets Supported Lanthanum Hydroxide Nanoparticles. Water Air Soil Pollut. 2014, 225. [CrossRef]

13. Singh, M.; Srivastava, R.K. Sequencing batch reactor technology for biological wastewater treatment: A review. Asia-Pac. J. Chem. Eng. 2011, 6, 3-13. [CrossRef]

14. Lai, L.; Xie, Q.; Chi, L.; Gu, W.; Wu, D. Adsorption of phosphate from water by easily separable $\mathrm{Fe}_{3} \mathrm{O}_{4} @ \mathrm{SiO}_{2}$ core/shell magnetic nanoparticles functionalized with hydrous lanthanum oxide. J. Colloid Interface Sci. 2016, 465, 76-82. [CrossRef] [PubMed]

15. Su, Y.; Cui, H.; Li, Q.; Gao, S.; Shang, J.K. Strong adsorption of phosphate by amorphous zirconium oxide nanoparticles. Water Res. 2013, 47, 5018-5026. [CrossRef] [PubMed]

16. Yuan, X.; Pan, G.; Chen, H.; Tian, B. Phosphorus fixation in lake sediments using $\mathrm{LaCl}_{3}$-modified clays. Ecol. Eng. 2009, 35, 1599-1602. [CrossRef]

17. Tu, C.; Wang, S.; Qiu, W.; Xie, R.; Hu, B. Phosphorus Removal from Aqueous Solution by Adsorption onto La-modified Clinoptilolite. MATEC Web Conf. 2016, 67, 07013. [CrossRef]

18. Zong, E.; Liu, X.; Wang, J.; Yang, S.; Jiang, J.; Fu, S. Facile preparation and characterization of lanthanum-loaded carboxylated multi-walled carbon nanotubes and their application for the adsorption of phosphate ions. J. Mater. Sci. 2017, 52, 7294-7310. [CrossRef]

19. Langmuir, I. The adsorption of gases on plane surfaces of glass, mica and platinum. J. Am. Chem. Soc. 1918, 40, 1361-1403. [CrossRef]

20. Freundlich, H. Über die adsorption in lösungen (adsorption in solution). Z. Phys. Chem. 1906, 57, $384-470$.

21. Butt, H.J.; Graf, K.; Kappl, M. Physical and Chemistry of Interfaces; Wiley-VCH Verlag GmbH \& Co. KGaA: Weinheim, Germany, 2004. 
22. Ma, H.; Pu, S.; Ma, J.; Yan, C.; Zinchenko, A.; Pei, X.; Chu, W. Formation of multi-layered chitosan honeycomb spheres via breath-figure-like approach in combination with co-precipitation processing. Mater. Lett. 2018, 211, 91-95. [CrossRef]

23. Zhou, J.; Yang, S.; Yu, J.; Shu, Z. Novel hollow microspheres of hierarchical zinc-aluminum layered double hydroxides and their enhanced adsorption capacity for phosphate in water. J. Hazard. Mater. 2011, 192, 1114-1121. [CrossRef] [PubMed]

24. Yan, L.; Xu, Y.; Yu, H.; Xin, X.; Wei, Q.; Du, B. Adsorption of phosphate from aqueous solution by hydroxy-aluminum, hydroxy-iron and hydroxy-iron-aluminum pillared bentonites. J. Hazard. Mater. 2010, 179, 244-250. [CrossRef] [PubMed]

25. Haghseresht, F.; Wang, S.; Do, D.D. A novel lanthanum-modified bentonite, Phoslock, for phosphate removal from wastewaters. Appl. Clay Sci. 2009, 46, 369-375. [CrossRef]

26. Zhou, Q.; Wang, X.; Liu, J.; Zhang, L. Phosphorus removal from wastewater using nano-particulates of hydrated ferric oxide doped activated carbon fiber prepared by Sol-Gel method. Chem. Eng. J. 2012, 200-202, 619-626. [CrossRef]

27. Huang, W.; Li, D.; Liu, Z.; Tao, Q.; Zhu, Y.; Yang, J.; Zhang, Y. Kinetics, isotherm, thermodynamic, and adsorption mechanism studies of $\mathrm{La}(\mathrm{OH})_{3}$-modified exfoliated vermiculites as highly efficient phosphate adsorbents. Chem. Eng. J. 2014, 236, 191-201. [CrossRef]

28. Kuroki, V.; Bosco, G.E.; Fadini, P.S.; Mozeto, A.A.; Cestari, A.R. Use of a La (III)-modified bentonite for effective phosphate removal from aqueous media. J. Hazard. Mater. 2014, 274, 124-131. [CrossRef] [PubMed]

29. Genz, A.; Kornmüller, A.; Jekel, M. Advanced phosphorus removal from membrane filtrates by adsorption on activated aluminium oxide and granulated ferric hydroxide. Water Res. 2004, 38, 3523-3530. [CrossRef] [PubMed]

30. Zamparas, M.; Gianni, A.; Stathi, P.; Deligiannakis, Y.; Zacharias, I. Removal of phosphate from natural waters using innovative modified bentonites. Appl. Clay Sci. 2012, 62-63, 101-106. [CrossRef]

31. Huang, W.; Li, D.; Yang, J.; Liu, Z.; Zhu, Y.; Tao, Q.; Xu, K.; Li, J.; Zhang, Y. One-pot synthesis of Fe (III)-coordinated diamino-functionalized mesoporous silica: Effect of functionalization degrees on structures and phosphate adsorption. Microporous Mesoporous Mater. 2013, 170, 200-210. [CrossRef]

(C) 2018 by the authors. Licensee MDPI, Basel, Switzerland. This article is an open access article distributed under the terms and conditions of the Creative Commons Attribution (CC BY) license (http://creativecommons.org/licenses/by/4.0/). 